\title{
A Small Cysteine-Rich Phytotoxic Protein of Phytophthora capsici Functions as Both Plant Defense Elicitor and Virulence Factor
}

\author{
Zi-Hui Zhang, ${ }^{1}$ Jing-Hao Jin, ${ }^{1,2}$ Gui-Lin Sheng, ${ }^{1}$ Yu-Ping Xing, ${ }^{1}$ Wang Liu, ${ }^{1}$ Xue Zhou, ${ }^{1}$ Yi-Qing Liu, ${ }^{1}$ and \\ Xiao-Ren Chen ${ }^{1,2, \dagger}$ \\ ${ }^{1}$ College of Horticulture and Plant Protection, Yangzhou University, 48 Wenhui Eastern Road, Yangzhou 225009, Jiangsu \\ Province, China \\ ${ }^{2}$ Joint International Research Laboratory of Agriculture and Agri-Product Safety of Ministry of Education of China, Yangzhou \\ University, 48 Wenhui Eastern Road, Yangzhou 225009, Jiangsu Province, China
}

Accepted 4 April 2021.

Small cysteine-rich (SCR) proteins, including fungal avirulence proteins, play important roles in pathogen-plant interactions. SCR protein-encoding genes have been discovered in the genomes of Phytophthora pathogens but their functions during pathogenesis remain obscure. Here, we report the characterization of one Phytophthora capsici SCR protein (namely, SCR82) with similarity to Phytophthora cactorum phytotoxic protein PcF. The scr82 gene has 10 allelic sequences in the $P$. capsici population. Homologs of SCR82 were not identified in fungi or other organisms but in Phytophthora relative species. Initially, scr82 was weakly expressed during the mycelium, sporangium, and zoospore stages but quickly upregulated when the infection initiated. Both ectopic expression of SCR82 and recombinant yeast-expressed protein (rSCR82) caused cell death on tomato leaves. Upon treatment, rSCR82 induced plant defense responses, including the induction of defense gene expression, reactive oxygen species burst, and callose deposition. Knockout of scr82 in $P$. capsici by CRISPR/Cas9 severely impaired its virulence on host plants and significantly reduced its resistance against oxidative stress. Inversely, its overexpression increased the pathogen's virulence and tolerance to oxidative stress. Our results collectively demonstrate that SCR82 functions as both an important virulence factor and plant defense elicitor, which is conserved across Phytophthora spp.

${ }^{\dagger}$ Corresponding author: X.-R. Chen; xrchen@yzu.edu.cn

Z.-H. Zhang, J.-H. Jin, and G.-L. Sheng contributed equally to this work.

Funding: This work was supported by the National Natural Science Foundation of China (grants 31871907 and 31671971), Jiangsu Agriculture Science and Technology Innovation Fund (grant CX(20)3125), the Open Project of Joint International Research Laboratory of Agriculture and Agri-Product Safety of Ministry of Education of China (grant JRK20180012), the Yangzhou University 2016 Project for Excellent Young Key Teachers, and High-Level Talent Support Program of Yangzhou University.

*The $\boldsymbol{e}$-Xtra logo stands for "electronic extra" and indicates that supplementary figures and supplementary tables are published online.

The author(s) declare no conflict of interest. distributed under the CC BY-NC-ND 4.0 International license.
Keywords: CRISPR/Cas9, oxidative stress, Phytophthora capsici, plant immunity, small cysteine-rich protein, virulence, yeast

Oomycetes are a phylogenetically unique class of fungus-like eukaryotic microorganisms, many of which are notorious worldwide for their massive devastation to crop plants. One of its genera, Phytophthora, consists of approximately 100 plant pathogens, including potato and tomato late blight agent Phytophthora infestans and the soybean root and stem rot agent $P$. sojae (Erwin and Ribeiro 1996). Unlike most Phytophthora spp. with narrow host ranges, $P$. capsici is responsible for big losses in the production of a wide variety of crops within the family Solanaceae (e.g., tomato, pepper, and eggplant), the Cucurbits (e.g., cucumber, pumpkin, squash, cantaloupe, and watermelon) and the family Leguminosae (e.g., snap bean) (Erwin and Ribeiro 1996; Kamoun et al. 2015; Lamour et al. 2012). It is estimated that the pathogen leads to annual losses of over $\$ 1$ billion in vegetable production worldwide (Lamour et al. 2012). Although P. capsici is a pathogen of great economic importance, the molecular mechanisms of pathogenicity are not well understood.

To achieve a successful infection and colonization, Phytophthora pathogens are thought to manipulate the physiological and defense network of targeted cells through two groups of secreted effectors, functioning either in the extracellular space (apoplastic effectors) or inside the plant cell (cytoplasmic effectors) (Kamoun 2006). In turn, to protect themselves from infection, plants have evolved a two-tier immune system: pathogen-associated molecular pattern (PAMP) (or microbe- or damage-associated molecular pattern)-triggered immunity (PTI) and effector-triggered immunity (ETI) (Jones and Dangl 2006). Cell surface localized pattern recognition receptors mediate the first layer of plant immunity (i.e., PTI) against a diversity of plant pathogens (Monaghan and Zipfel 2012). PTI initiates the induction of various antimicrobial responses, including the generation of reactive oxygen species (ROS), synthesis of salicylic acid, expression of plant defense genes, stomatal closure, callose accumulation, and localized programmed cell death (Couto and Zipfel 2016; Wang et al. 2019). Nevertheless, successful pathogens have developed strategies to either evade or suppress PTI by delivery of a large variety of effectors into the apoplast, cytoplasm, and other host subcellular compartments (Bozkurt et al. 2012; Wang et al. 2019). However, plants have evolved structurally conserved disease resistance proteins as intracellular receptors to recognize pathogen effectors (here, namely, avirulence [Avr] proteins), leading to activation 
of ETI, the second layer of plant immunity (Jones and Dangl 2006; Wang et al. 2019).

To break down the first barrier, apoplastic effectors interact with surface proteins and other extracellular molecules such as defenserelated enzymes and protease inhibitors to perturb their functions, therefore enabling parasitism (Wang and Jiao 2019; Wang and Wang 2018). Some known apoplastic effectors include elicitins, cellulose-binding, elicitor, and lectin-like proteins; necrosis- and ethylene-inducing peptide 1-like proteins (NLPs), enzyme inhibitors; and P. cactorum-Fragaria $(\mathrm{PcF}) / \mathrm{small}$ cysteine-rich (SCR) proteins (Kamoun 2006). The PcF/SCR protein family represents one group of SCR secretory proteins, a feature reminiscent of Avr proteins from plant-pathogenic fungi (Stergiopoulos and de Wit 2009). The first member (i.e., PcF) was purified from the culture filtrates of $P$. cactorum and identified to be toxic on both tomato and strawberry (Orsomando et al. 2001, 2003). Other members have been gradually annotated into this family during the genome sequencing of oomycete species such as $P$. infestans, $P$. sojae, $P$. ramorum, Pythium ultimum, and Hyaloperonospora arabidopsidis (Baxter et al. 2010; Haas et al. 2009; Lévesque et al. 2010; Tyler et al. 2006). They were identified by the abbreviation 'SCR' followed by the residue number, such as SCR74 from Phytophthora infestans and SCR96 from P. cactorum (Bos et al. 2003; Chen et al. 2016; Liu et al. 2005). Although the PcF/SCR family or PcF toxin family (Pfam 09461) was already proposed based on the phytotoxic activity of PcF, studies on the family have lagged behind those in other effector families (Nicastro et al. 2009; Stassen and Van den Ackerveken 2011).

$\mathrm{PcF} / \mathrm{SCR}$ proteins were initially regarded as candidate Avr proteins in oomycetes because they share a range of the features with fungal Avr proteins (e.g., those of Cladosporium fulvum and Magnaporthe oryzae), including N-terminal secretory signal, relatively short length $(\leq 300$ amino acids [aa]), cysteine pattern, and upregulated expression profile during the pathogen infection (Bos et al. 2003; Liu et al. 2005; Stergiopoulos and de Wit 2009; Wawra et al. 2012). However, unlike fungal Avr proteins, none of their host interactors has been identified yet. To date, PcF and SCR96 from $P$. cactorum are the only two characterized members within the family. Both of them behave as phytotoxic proteins leading to plant cell death (PCD), possibly through a surface-exposed amino acid stretch SK(E/C)C (Chen et al. 2016; Orsomando et al. 2001, 2011). Silencing of scr96 in P. cactorum compromised the pathogen virulence on plants and reduced its resistance against oxidative stress (Chen et al. 2016). Together with the finding that $\mathrm{PcF}$ shows structural similarity to Ole-e6, a major allergen from olive tree pollen (Nicastro et al. 2009), PcF/SCR proteins may play different roles in the pathogenesis of Phytophthora pathogens. Because these proteins can form disulfide bonds through cysteine residues, they are believed to be stable in the harsh apoplast environment (Huang et al. 2020; Kamoun 2006). Except for S-S bridges, canonical protein domains and motifs as found in cytoplasmic RXLR and $\mathrm{CRN}$ effectors are absent from PcF/SCR proteins. Despite some progress having been made in the past, their action mechanism and biological functions remain largely unknown.

In this study, we studied a previously predicted PcF/SCR effector protein in P. capsici, SCR82 (Chen et al. 2013), in the respect of its sequence polymorphism in the pathogen population, homolog genes in Phytophthora relative species, gene transcriptional profiling, plant transient expression, yeast recombinant protein expression, plant defense responses, and gene knockout. Our data allow us to conclude that SCR82 has dual roles as a plant defense elicitor and an important virulence factor, and provides a solid basis to further characterize PcF/SCR effectors involved in the interactions of Phytophthora pathogens with host plants.

\section{RESULTS}

SCR82 has allelic sequences in the $P$. capsici population.

Previously, we analyzed gene expression changes of $P$. capsici across three stages (mycelium [MY], zoospore [ZO], and germinating cyst $[\mathrm{GC}]$ ) using Illumina RNA Sequencing (RNA-Seq). A number of differentially expressed genes was identified, including scr82 (GenBank accession number KT215396) (Chen et al. 2013). The scr82 gene does not contain introns and its open reading frame (ORF) is 249 bp long, which encodes an 82-aa PcF/SCR protein containing seven cysteines. SignalP analysis of the predicted protein identified a 21-aa signal peptide with a significant mean $S$ value of 0.916 (Fig. 1).

To examine sequence polymorphism of the scr 82 gene, we used high-fidelity PCR amplification with primers flanking its ORF, followed by DNA sequencing. Ten alleles of scr82 encoding seven different amino acid sequences were identified in 44 isolates (Fig. 1; Supplementary Table S1; Supplementary Fig. S1). Most of the polymorphic sites were in the coding region of mature protein sequences, whereas only one site of the signal peptide region nucleotides was polymorphic (Supplementary Fig. S1). Thirteen site variations at DNA level were detected, leading to variations in four amino acid sites that are all located in the mature protein sequences (Fig. 1; Supplementary Fig. S1). The alleles scr82_3, scr82_4, and scr82_7 correspond to the same isoform of SCR82 while scr82_1 and scr82_9 encode another SCR82 isoform. Multiple alignments of the seven predicted SCR82 amino acid sequences revealed that the conserved cysteine residues define the family signature (Fig. 1).

The natural selection pressure underlying sequence polymorphism of SCR82 was characterized by calculating the ratio of the nonsynonymous substitution rate $(\mathrm{d} N)$ to the synonymous substitution rate $(\mathrm{d} S)$ across the entire ORF sequences, signal peptides, and mature protein sequences (Table 1). The Yn00 tool of the PAML v4.3 software package (Yang 2007) was utilized to calculate the ratios. The 45 pairwise comparisons of 10 allelic sequences showed that the $\mathrm{d} N / d S$ values were lower than unity, suggesting evidence of purifying selection pressure in the scr82 gene, especially in the mature protein sequence (Table 1). The codon-based maximum-likelihood IFEL tool in the Datamonkey suite (Delport et al. 2010; Kosakovsky Pond and Frost 2005) revealed that four codons $(45 \mathrm{R}, 61 \mathrm{D}, 62 \mathrm{~S}$, and $69 \mathrm{E})$ of $s c r 82$ were found to be under negative selection $(P<0.1)$.

\section{SCR82 is a Phytophthora-specific effector.}

Conserved domain analysis revealed nothing but an even number $(n=6)$ of cysteine residues in the mature protein sequences

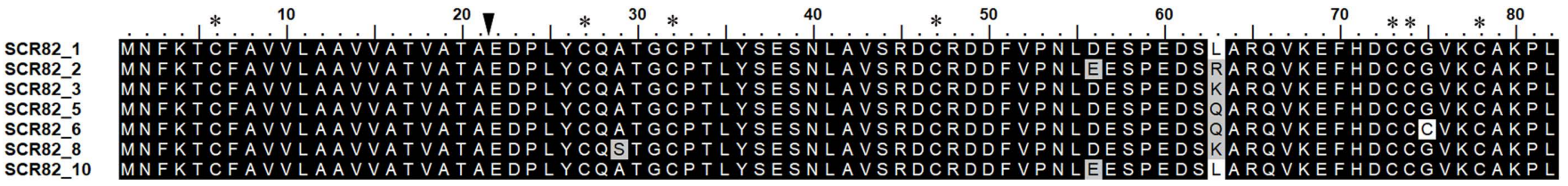

Fig. 1. Multiple sequence alignment of seven SCR82 amino acid sequences from Phytophthora capsici. Single-letter amino acid codes were used. Residue numbers are denoted above the sequences. The predicted cleavage site of signal peptide is denoted by an arrow immediately after the 21 st residue. The seven conserved cysteine residues are indicated by asterisks. The sequence labels correspond to those labels of allelic sequences in Supplementary Figure S1. The most common allelic sequence was on the top, labeled as SCR82_1. 
(Fig. 1). To get more annotation about SCR82, we investigated its homologs in other organisms by performing BLASTP comparisons against the FungiDB, NCBI, and genome databases of various oomycetes. Sequence blasting retrieved homologs of SCR82 only from Phytophthora spp., including $P$. ramorum, $P$. infestans, $P$. parasitica, $P$. cinnamomi, $P$. cactorum, and $P$. palmivora. No homologs of SCR82 were identified from fungi or other organisms. The sequence alignment revealed a high conservation of SCR82 within the genus Phytophthora (Fig. 2A). Phylogenetic trees demonstrated the evolutionary relationship between SCR82 and its homologs, with the homolog (PITG22677) from P. infestans as the closest relative (Fig. 2B). Both showed $71 \%$ sequence similarity to each other (Fig. 2A). Furthermore, SCR82 shared $59 \%$ sequence identity with $P$. cactorum PcF (Fig. 2A).

scr82 is upregulated during in planta infection by $\boldsymbol{P}$. capsici.

Previously, we examined global gene expression changes of $P$. capsici across three life cycles (i.e., MY, ZO, and GC) (Chen et al. 2013). By mining this RNA-Seq dataset, we found that the scr82 gene was highly upregulated in GC, a preinfection stage of P. capsici, compared with MY, sporangium (SP), and ZO (Fig. 3A).

To determine whether SCR82 is involved in the host infection, real-time reverse-transcription PCR (qRT-PCR) analysis was conducted. The expression of scr 82 was investigated using cDNA templates derived from infected Nicotiana benthamiana $(1.5,3$, $6,12,24,36$, and $72 \mathrm{~h}$ postinoculation [hpi]), uninfected N. benthamiana, and four life cycles of $P$. capsici (MY, SP, ZO, and GC) (Fig. 3B). Expression of scr82 in different samples was compared with the level of its expression in a calibrator sample, which was MY cDNA and assigned the value of 1.0. The scr82 gene was upregulated nearly 15 -fold at the GC stage and showed elevated levels of expression throughout infection. In particular, scr82 transcripts were detected with high amount at early stages of infection, reached maximal level at $24 \mathrm{hpi}$, and then declined at later stages of infection. Repeated amplifications with different sets of cDNA samples resulted in similar expression profiles. qRT-PCR was also

Table 1. Ratio of the nonsynonymous substitution rate $(\mathrm{d} N)$ to the synonymous substitution rate $(\mathrm{d} S)$ analysis of pairwise comparisons of $s c r 82$ alleles ${ }^{\mathrm{a}}$

\begin{tabular}{|c|c|c|c|c|c|c|c|c|c|c|}
\hline \multicolumn{2}{|c|}{ Pairwise comparison } & \multicolumn{3}{|c|}{ Full sequence } & \multicolumn{3}{|c|}{ Signal peptide } & \multicolumn{3}{|c|}{ Mature protein region } \\
\hline Seq. 1 & Seq. 2 & $\mathrm{~d} N / \mathrm{d} S$ & $\mathrm{~d} N$ & $\mathrm{~d} S$ & $\mathrm{~d} N / \mathrm{d} S$ & $\mathrm{~d} N$ & $\mathrm{~d} S$ & $\mathrm{~d} N / \mathrm{d} S$ & $\mathrm{~d} N$ & $\mathrm{~d} S$ \\
\hline scr82_2 & scr82_1 & 0.2054 & 0.0176 & 0.0857 & 0 & 0 & 0.0512 & 0.2249 & 0.0231 & 0.1027 \\
\hline scr82_3 & scr82_1 & 0.1304 & 0.0128 & 0.0982 & 0 & 0 & 0.0512 & 0.1405 & 0.0168 & 0.1196 \\
\hline scr82_3 & scr82_2 & 0.2158 & 0.0109 & 0.0505 & - & 0 & 0 & 0.1830 & 0.0142 & 0.0776 \\
\hline scr82_4 & scr82_1 & 0.2698 & 0.0126 & 0.0467 & - & 0 & 0 & 0.2402 & 0.0166 & 0.0691 \\
\hline scr82_4 & scr82_2 & 0.3112 & 0.0108 & 0.0347 & 0 & 0 & 0.0512 & 0.5364 & 0.0140 & 0.0261 \\
\hline scr82_4 & scr82_3 & 0 & 0 & 0.0505 & 0 & 0 & 0.0512 & 0 & 0 & 0.0493 \\
\hline scr82_5 & scr82_1 & 0.0770 & 0.0054 & 0.0701 & 0 & 0 & 0.0512 & 0.0887 & 0.0070 & 0.0789 \\
\hline scr82_5 & scr82_2 & 0.3178 & 0.0136 & 0.0428 & - & 0 & 0 & 0.2627 & 0.0176 & 0.0670 \\
\hline scr82_5 & scr82_3 & 0.1104 & 0.0055 & 0.0498 & - & 0 & 0 & 0.0940 & 0.0071 & 0.0755 \\
\hline scr82_5 & scr82_4 & 0.1574 & 0.0054 & 0.0343 & 0 & 0 & 0.0512 & 0.2745 & 0.0070 & 0.0255 \\
\hline scr82_6 & scr82_1 & 0.1534 & 0.0108 & 0.0704 & 0 & 0 & 0.0512 & 0.1774 & 0.0141 & 0.0795 \\
\hline scr82_6 & scr82_2 & 0.4419 & 0.0190 & 0.0430 & - & 0 & 0 & 0.3654 & 0.0247 & 0.0676 \\
\hline scr82_6 & scr82_3 & 0.2200 & 0.0110 & 0.0500 & - & 0 & 0 & 0.1879 & 0.0143 & 0.0761 \\
\hline scr82_6 & scr82_4 & 0.3140 & 0.0108 & 0.0344 & 0 & 0 & 0.0512 & 0.5508 & 0.0141 & 0.0256 \\
\hline scr82_6 & scr82_5 & $\infty$ & 0.0054 & 0 & - & 0 & 0 & $\infty$ & 0.0070 & 0 \\
\hline scr82_7 & scr82_1 & 0.1080 & 0.0128 & 0.1185 & 0 & 0 & 0.0512 & 0.1131 & 0.0169 & 0.1494 \\
\hline scr82_7 & scr82_2 & 0.1639 & 0.0110 & 0.0671 & - & 0 & 0 & 0.1390 & 0.0143 & 0.1029 \\
\hline scr82_7 & scr82_3 & 0 & 0 & 0.0157 & - & 0 & 0 & 0 & 0 & 0.0230 \\
\hline scr82_7 & scr82_4 & 0 & 0 & 0.0680 & 0 & 0 & 0.0512 & 0 & 0 & 0.0743 \\
\hline scr82_7 & scr82_5 & 0.0821 & 0.0055 & 0.0670 & - & 0 & 0 & 0.0706 & 0.0072 & 0.1020 \\
\hline scr82_7 & scr82_6 & 0.1634 & 0.0110 & 0.0673 & - & 0 & 0 & 0.1402 & 0.0144 & 0.1027 \\
\hline scr $82 \_8$ & scr82_1 & 0.1854 & 0.0183 & 0.0987 & 0 & 0 & 0.0512 & 0.2003 & 0.0241 & 0.1203 \\
\hline scr82_8 & scr82_2 & 0.3228 & 0.0164 & 0.0508 & - & 0 & 0 & 0.2737 & 0.0214 & 0.0782 \\
\hline scr $82 \_8$ & scr82_3 & $\infty$ & 0.0055 & 0 & - & 0 & 0 & $\infty$ & 0.0072 & 0 \\
\hline scr82_8 & scr82_4 & 0.1063 & 0.0054 & 0.0508 & 0 & 0 & 0.0512 & 0.1431 & 0.0071 & 0.0496 \\
\hline scr82_8 & scr82_5 & 0.2196 & 0.011 & 0.0501 & - & 0 & 0 & 0.1882 & 0.0143 & 0.0760 \\
\hline scr82_8 & scr82_6 & 0.3280 & 0.0165 & 0.0503 & - & 0 & 0 & 0.2810 & 0.0215 & 0.0765 \\
\hline scr $82 \_8$ & scr82_7 & 0.3481 & 0.0055 & 0.0158 & - & 0 & 0 & 0.3117 & 0.0072 & 0.0231 \\
\hline scr82_9 & scr82_1 & 0 & 0 & 0.0168 & 0 & 0 & 0.0512 & - & 0 & 0 \\
\hline scr82_9 & scr82_2 & 0.2730 & 0.0178 & 0.0652 & - & 0 & 0 & 0.2249 & 0.0231 & 0.1027 \\
\hline scr82_9 & scr82_3 & 0.1631 & 0.0128 & 0.0785 & - & 0 & 0 & 0.1405 & 0.0168 & 0.1196 \\
\hline scr82_9 & scr82_4 & 0.1994 & 0.0127 & 0.0637 & 0 & 0 & 0.0512 & 0.2402 & 0.0166 & 0.0691 \\
\hline scr82_9 & scr82_5 & 0.1059 & 0.0054 & 0.0510 & - & 0 & 0 & 0.0887 & 0.0070 & 0.0789 \\
\hline scr82_9 & scr82_6 & 0.2129 & 0.0109 & 0.0512 & - & 0 & 0 & 0.1774 & 0.0141 & 0.0795 \\
\hline scr82_9 & scr82_7 & 0.1329 & 0.0129 & 0.0971 & - & 0 & 0 & 0.1131 & 0.0169 & 0.1494 \\
\hline scr82_9 & scr82_8 & 0.2332 & 0.0184 & 0.0789 & - & 0 & 0 & 0.2003 & 0.0241 & 0.1203 \\
\hline scr82_10 & scr82_1 & $\infty$ & 0.0054 & 0 & - & 0 & 0 & $\infty$ & 0.0070 & 0 \\
\hline scr82_10 & scr82_2 & 0.1400 & 0.0121 & 0.0864 & 0 & 0 & 0.0512 & 0.1521 & 0.0158 & 0.1039 \\
\hline scr82_10 & scr82_3 & 0.1852 & 0.0183 & 0.0988 & 0 & 0 & 0.0512 & 0.1987 & 0.0240 & 0.1208 \\
\hline scr82_10 & scr82_4 & 0.3830 & 0.0180 & 0.0470 & - & 0 & 0 & 0.3395 & 0.0237 & 0.0698 \\
\hline scr82_10 & scr82_5 & 0.1532 & 0.0108 & 0.0705 & 0 & 0 & 0.0512 & 0.1771 & 0.0141 & 0.0796 \\
\hline scr82_10 & scr82_6 & 0.2302 & 0.0163 & 0.0708 & 0 & 0 & 0.0512 & 0.2656 & 0.0213 & 0.0802 \\
\hline scr82_10 & scr82_7 & 0.1544 & 0.0184 & 0.1192 & 0 & 0 & 0.0512 & 0.1604 & 0.0242 & 0.1509 \\
\hline scr82_10 & scr82_8 & 0.2397 & 0.0238 & 0.0993 & 0 & 0 & 0.0512 & 0.2584 & 0.0314 & 0.1215 \\
\hline scr82_10 & scr82_9 & 0.3195 & 0.0054 & 0.0169 & 0 & 0 & 0.0512 & $\infty$ & 0.007 & 0 \\
\hline
\end{tabular}

\footnotetext{
${ }^{\text {a }}$ Seq. $=$ sequence. The $\infty$ in column $\mathrm{d} N / \mathrm{d} S$ refers to pairwise comparisons in which $\mathrm{d} N>0$ and $\mathrm{d} S=0$, and - refers to pairwise comparisons in which $\mathrm{d} N=0$ and $\mathrm{d} S=0$. Signal peptide refers to the sequence from the 1 st to the 21 st, and the mature protein region refers to the sequence from the immediate residue after signal peptide to the end, except the stop codon.
} 
performed to analyze the gene expression changes during the infection of bell pepper leaves. A similar gene expression pattern was observed (Supplementary Fig. S2)

\section{SCR82 triggers PCD in tomato.}

Ectopic expression of scr82 in tomato and $N$. benthamiana was performed using Agrobacterium tumefaciens-mediated transformation (agroinfection) (Fig. 4A). Different ORFs corresponding to seven SCR82 isoforms, including the signal peptide region, were individually cloned into the binary Potato virus X (PVX) vector pGR107 (Jones et al. 1999). Transient expression of scr82_1 and scr82_3 but not other genes induced visible PCD as vigorously as the positive control scr99 from $P$. cactorum (Chen et al. 2016) in tomato leaves at 4 days postinfiltration (Fig. 4A). We then performed similar agroinfections on $N$. benthamiana, which is susceptible to the infection of $P$. capsici (Chen et al. 2013). However, none of SCR 82 isoforms could induce cell death on $N$. benthamiana leaves.

To further confirm the PCD-inducing activity, we expressed and purified the recombinant protein of SCR82 (rSCR82-His 6 ) using

A

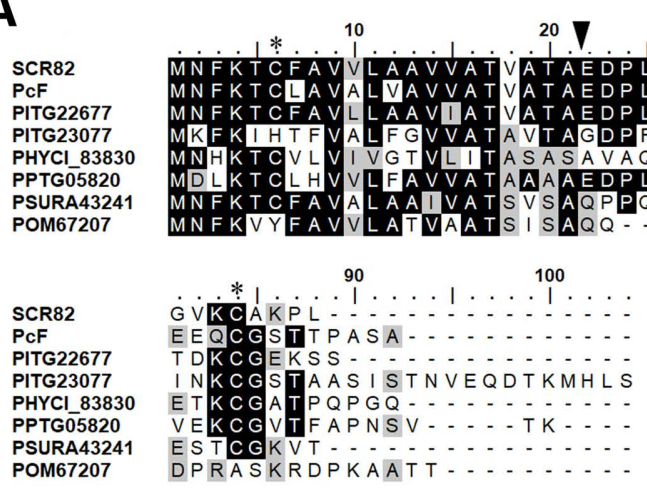

B

PITG23077 (P. infestans)

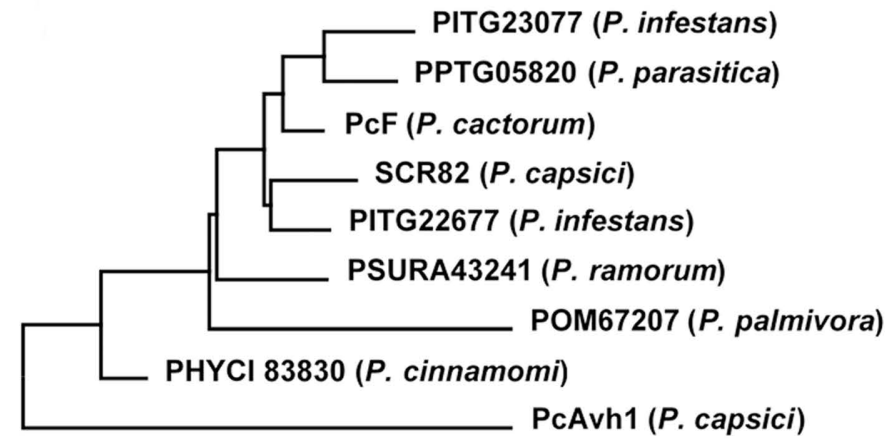

PcAvh1 (P. capsici)

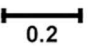

Fig. 2. Protein sequence alignment and phylogenetic analysis of Phytophthora capsici SCR 82 and its homologs. A, Protein sequences were aligned and shaded for consensus (50\% threshold for shading). The predicted cleavage site for the signal peptide of SCR82 is indicated by an arrow and its seven conserved cysteine residues by asterisks on the top of the sequences. B, Phylogeny tree of SCR82 and its homologs with locus tags from different Phytophthora spp. Five homologs (PITG23077, PITG22677, PPTG05820, PSURA43241, and PHYCI83830) were downloaded from FungiDB while the other two (PcF and POM67207) are from the NCBI database. The P. capsici RXLR effector PcAvh1 (Chen et al. 2019) served as an outgroup in the neighbor-joining tree.

A

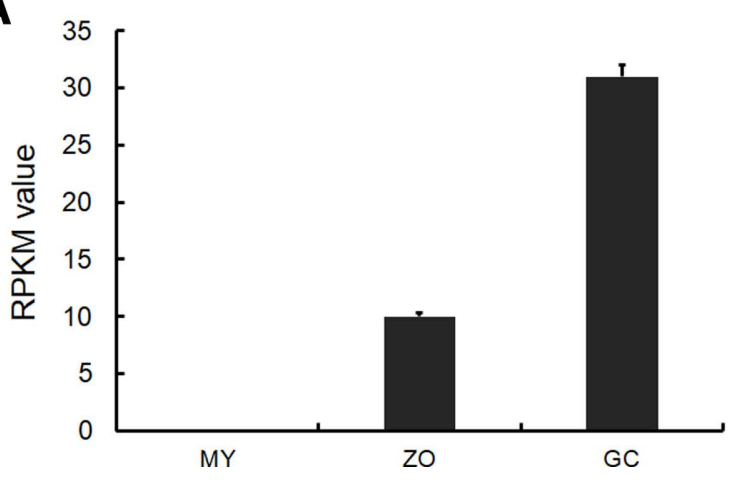

B

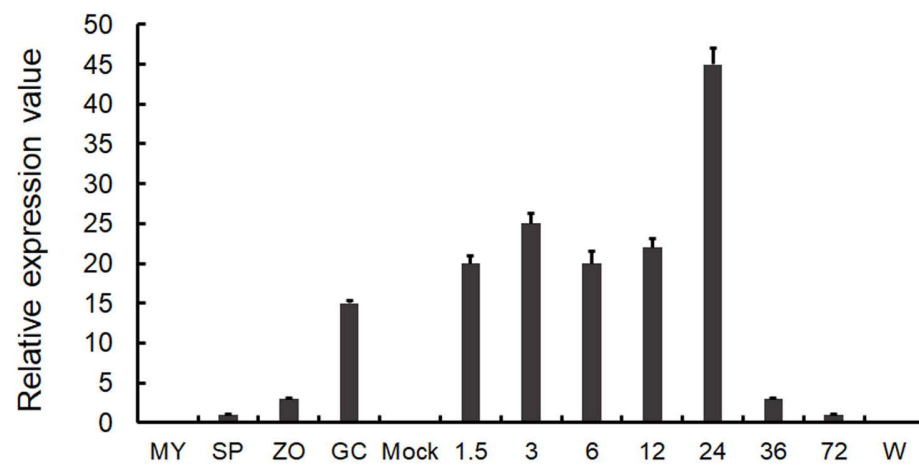

Fig. 3. Expression level of scr82 during the developmental and infection stages of Phytophthora capsici. A, The gene expression level was determined by calculating the number of reads for the gene and then normalizing this to the reads per kilobase of exon model per million mapped reads (RPKM). The RPKM values of scr82 were calculated in this study using RNA-Sequencing data (GenBank Sequence Read Archive accession number SRP 024305). B, The gene expression level was determined by real-time reverse-transcription (qRT)-PCR. MY = vegetative mycelia; $\mathrm{SP}=$ sporangia; $\mathrm{ZO}=$ zoospores; $\mathrm{GC}=$ germinating cysts; and 1.5 to $72=$ Nicotiana benthamiana roots at $1.5,3,6,12,24,36$, and $72 \mathrm{~h}$ postinoculation. Sterile water (W) and cDNA from W-inoculated plants (Mock) were used as negative control templates in qRT-PCR. 
the Pichia expression system (Fig. 4B). The ORFs of SCR82_1 and SCR82_3 without the secretion signals were cloned into the vector $\mathrm{pPIC} 9 \mathrm{~K}$, in frame with the $\alpha$-factor secretion signal sequence. After induction and purification, up to $140 \mu \mathrm{M}$ rSCR82 (approximately $14 \mathrm{kDa}$ ) was obtained and tested for its bioactivity (Fig. 4C). As expected, rSCR82 (but not the empty vector control) caused $\mathrm{PCD}$ as soon as at $30 \mathrm{~h}$ postinfiltration of tomato leaves. The PCD-triggering activity was in a dosedependent manner. Similarly, rSCR82 couldn't induce PCD on $N$. benthamiana leaves.

\section{SCR82 induces plant defense responses.}

Because some SCR effectors such as Avr proteins are often recognized by their receptors to trigger plant immunity, we investigated whether plant immunity responses could be induced by SCR82. ROS, as an important component in plant immunity systems under stress, might activate a series of resistance reactions in plant cells as a second messenger (Lamb and Dixon 1997; Levine et al. 1994). Considering this, we investigated ROS production using 3,3'-diaminobenzidine (DAB)-histochemical staining after plant treatment by rSCR82. It was shown that rSCR82 apparently triggered the ROS burst at $20 \mathrm{~h}$ posttreatment (hpt) in tomato leaves compared with the controls (Fig. 5A). We also examined callose deposition under the same conditions because cell wall defenses, exemplified by callose deposition, are typically triggered by PAMPs (Gómez-Gómez et al. 1999). At 20 hpt, massive callosities accumulated in rSCR82-treated tomato leaves compared with the control leaves (Fig. 5B).

We further investigated the induction of 19 defense-associated genes in tomato leaves to determine the extent of plant immunity upon rSCR82 treatment. These genes include four PTI marker genes (PTI5, WRKY28, LRR22, and GRAS2), pathogenesis-related genes (PRs), FLS2, and PAL (Supplementary Table S2). The

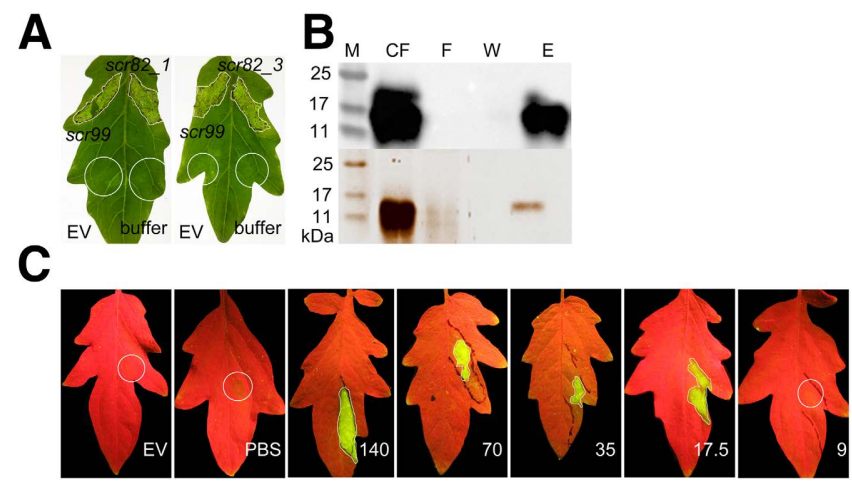

Fig. 4. Phytophthora capsici SCR82 caused plant cell death (PCD) on tomato leaves. A, Tomato cultivar L402 leaves were infiltrated with Agrobacterium tumefaciens strain GV3101 cells to express the different isoforms of SCR82. The expression of scr82_1 (left leaf) and scr82_3 (right leaf) triggered PCD as vigorously as the positive control scr 99 whereas the negative control (empty vector $[\mathrm{EV}]$ ) and the infiltration buffer didn't. B, The recombinant SCR82 protein from yeast KM71 cells was analyzed by Western blot using anti-His antibody (upper panel) and silver staining (lower panel). $\mathrm{M}=$ protein marker, $\mathrm{CF}=\mathrm{KM} 71$ culture filtrate, $\mathrm{F}=$ flow-through sample from the Ni-NTA affinity purification column of the culture filtrate, $\mathrm{W}=$ washing portions of the column, and $\mathrm{E}=$ the eluted protein sample of the column. C, The recombinant SCR82 protein triggered PCD in tomato in a dose-dependent manner. Tomato leaves were infiltrated with the purified protein sample with no dilution $(140 \mu \mathrm{M})$ or 1:2 dilutions in phosphate-buffered saline buffer. $\mathrm{EV}=$ empty vector used as the negative control. Laves were examined under normal light (A) or UV exposure (C). Irregular-shaped areas and circles are necrotic tissues and infiltration sites, respectively (A and C). Photographs were taken 4 days (A) or $30 \mathrm{~h}(\mathrm{C})$ after infiltrations. Data derived from scr82_1 was demonstrated as the example in panels $\mathbf{B}$ and $\mathbf{C}$.
mRNA levels of all of the genes were significantly increased by rSCR82 in tomato leaves (Fig. 6). In particular, the increased mRNA abundance of PTI marker genes and FLS2 indicated that defense responses were triggered by rSCR 82 in tomato leaves.

\section{SCR82 is important for the $P$. capsici pathogenesis in host plants.}

The above results indicate that SCR82 is involved in the $P$. capsici infection of host plants. To further investigate its potential virulence role, scr82 gene knockout (KO) mutants were generated using a CRISPR/Cas9 strategy (Fang et al. 2017). Three positive transformants $(\mathrm{KO} 1, \mathrm{KO} 2$, and $\mathrm{KO} 3)$ were verified by PCR and sequencing (Fig. 7A to E). A nonknockout transformant (transformation control [Ctrl]) served as a negative control. All of them exhibited normal developmental phenotypes, including filamentous growth, sporangium production, and zoospore release (vegetative growth analysis as an example shown in Supplementary Fig. S3). However, virulence tests showed that the mutants caused lesions significantly smaller than those of the Ctrl on both $N$. benthamiana leaves (Fig. 8A) and bell pepper stems (Fig. 8B), indicating that knockout of scr82 seriously impaired the virulence of $P$. capsici.

To verify the result, three complementation strains $(\mathrm{C} 1, \mathrm{C} 2$, and C3) were made by introducing pTORmRFP4 (Torche 2004) containing the full-length scr82 into the scr82 knockout mutant KO1 (Fig. 7E). Expression of scr82 and reduced virulence activity in KO1 were restored to levels comparable with controls (Figs. 7E and 8). To further elucidate the virulence function of SCR82, we generated two overexpression strains (OX1 and OX2) by introducing pTORmRFP4::scr82 into the wild-type (WT) strain (Fig. $7 \mathrm{E})$. In contrast to the $\mathrm{KO}$ mutants, the overexpression strains showed increased virulence compared with the WT (Fig. 8). All of the strains, including the $\mathrm{KO}$ mutants, the complementation strains, and the overexpression strains, are similar to the WT and Ctrl in developmental phenotypes, including vegetative growth (Supplementary Fig. S3). Altogether, the results indicate that SCR82 is important for the virulence of $P$. capsici.

\section{SCR82 is associated with oxidative stress tolerance.}

The generation of ROS in response to pathogen attack is a ubiquitous early part of the resistance mechanisms of plant cells (Lamb and Dixon 1997). It has been found that some Phytophthora proteins contribute to the pathogens' virulence through involvement in defense against oxidative stress (Chen et al. 2016; GamboaMeléndez et al. 2013; Gao et al. 2015). To gain further insight into the virulence role of SCR82 during infection, the scr82 knockout mutants, complementation strains, overexpression strains, Ctrl, and WT were inoculated onto Plich's agar medium containing a series of concentration of an exogenous oxidant, Cumeme hydroperoxide $(0,0.01,0.02$, and $0.03 \mathrm{mM})$ (Fig. 9A). The growth inhibition rates of the strains by the oxidant were compared (Fig. 9B). All of the derivative strains showed no significant difference in
A

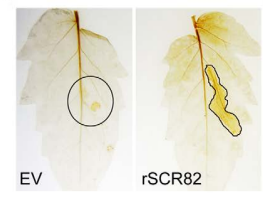

B

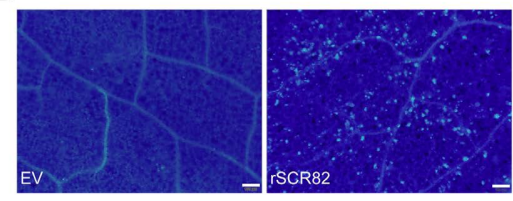

Fig. 5. SCR82 activates reactive oxygen species (ROS) burst and callose deposition in tomato leaves. Tomato leaves were infiltrated with $35 \mu \mathrm{M}$ rSCR82 or empty vector control (EV) after $20 \mathrm{~h} \mathrm{~A}$, ROS burst. The irregular-shaped area and circle are 3,3'-diaminobenzidine-histochemical staining of ROS formation and infiltration site, respectively. B, Callose deposition. Bars $=100 \mu \mathrm{m}$. Data derived from scr82_1 were demonstrated here as the example. 
mycelial growth on Plich's agar medium with $0.01 \mathrm{mM}$ Cumeme hydroperoxide or without Cumeme hydroperoxide when compared with the Ctrl and WT strains. However, the difference between the mutants, overexpression strains, and the controls in mycelial growth became significant when Cumeme hydroperoxide was at $0.02 \mathrm{mM}$. At $0.03 \mathrm{mM}$ Cumeme hydroperoxide, the $\mathrm{KO}$ mutants were almost unable to grow whereas the Ctrl and WT strains still proliferated. In contrast, gene overexpression increased the growth ability of the pathogen on such media. The complementation strains behaved like the controls. These data collectively suggest that SCR82 contributes to oxidative stress tolerance of $P$. capsici.

\section{DISCUSSION}

$P$. capsici is a typical hemibiotrophic oomycete pathogen that produces peptides and small molecules to manipulate the physiological processes and defense responses of host plants. Increasing
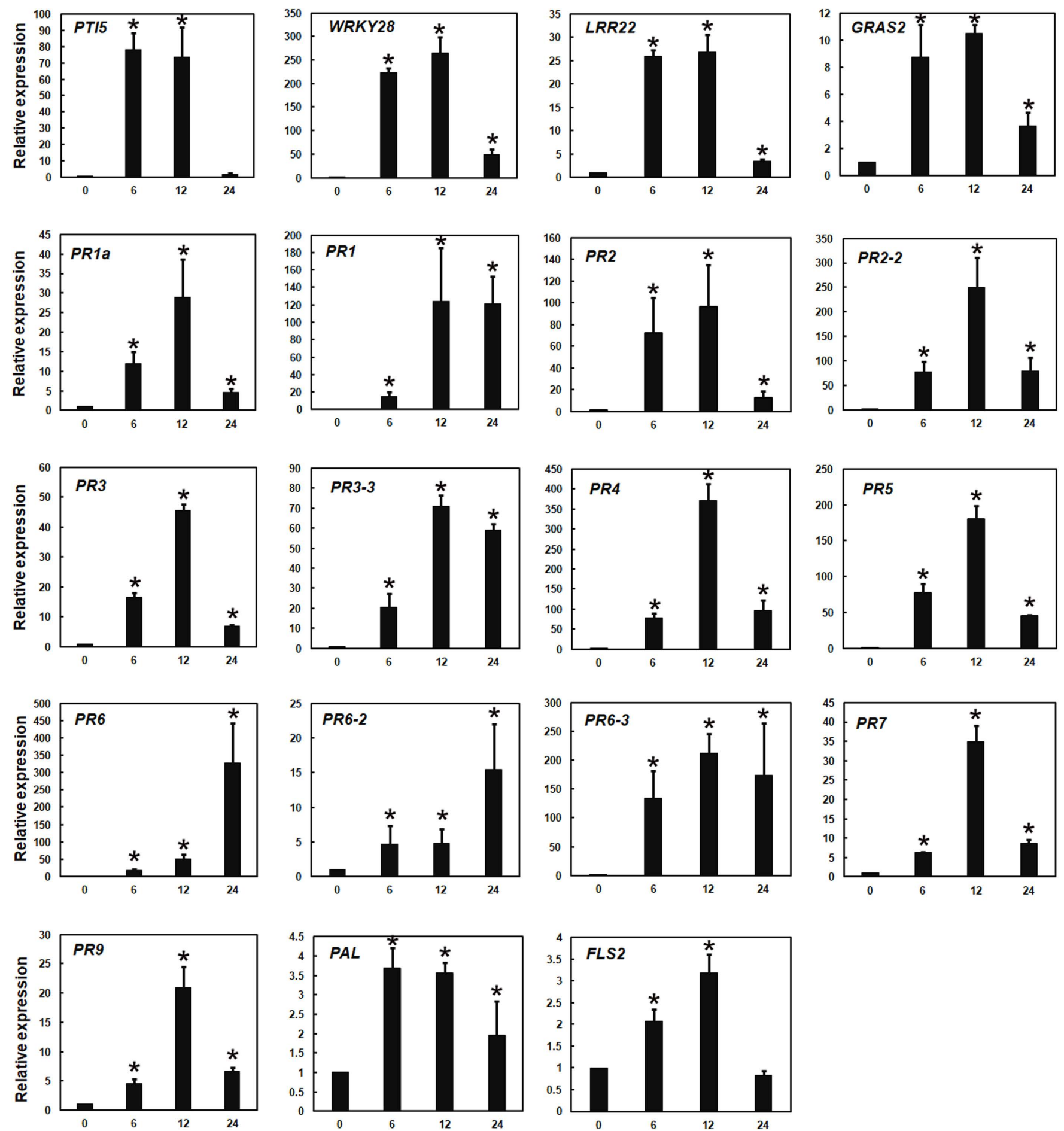

Fig. 6. Induction of defense-related gene expression by SCR 82 treatment in tomato leaves. Tomato leaves were infiltrated with $35 \mu \mathrm{M} \mathrm{rSCR} 82$, collected at designated time points $(0,6,12$, and $24 \mathrm{~h}$ posttreatment [hpt]) and used for real-time reverse-transcription PCR analysis. Calculated values for each gene were normalized with the actin gene and the final fold-change levels compared with $0 \mathrm{hpt}$, set as 1, are shown. Data presented are the average of values from three independent experiments (three technical replicates for each) \pm standard error. Significantly different fold changes $(P<0.05$, paired Student's $t$ test $)$ are indicated with an asterisk $(*)$. Data derived from $s c r 82 \_1$ were demonstrated here as the example. 


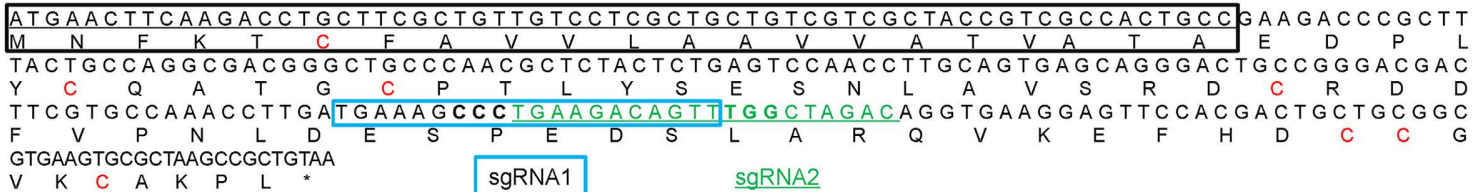

$\begin{array}{llll}V & \text { K C A K P L } & \text { SgRNA2 }\end{array}$

\section{B}

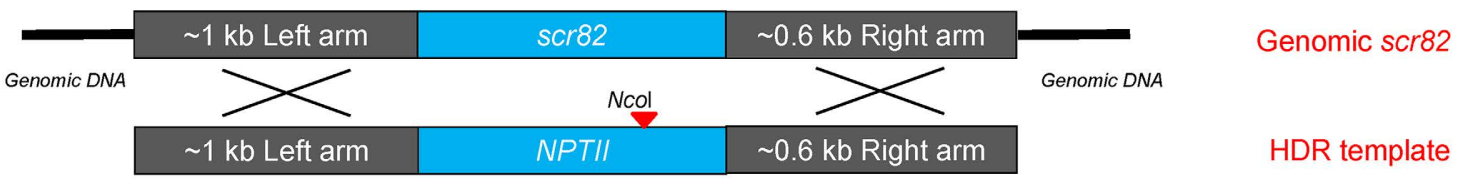

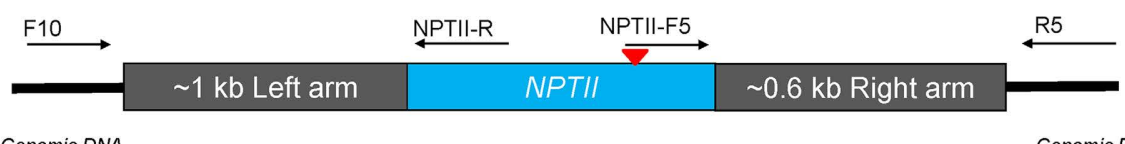
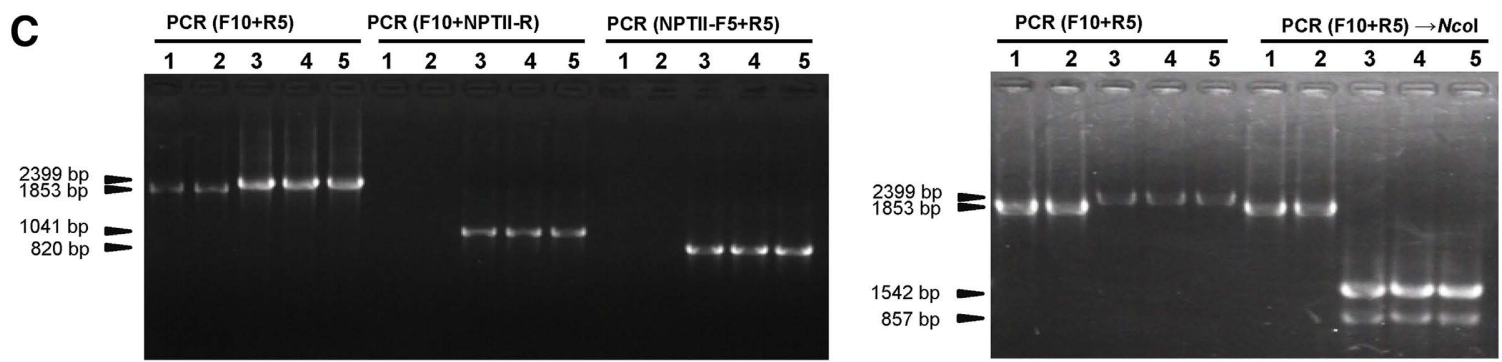

D
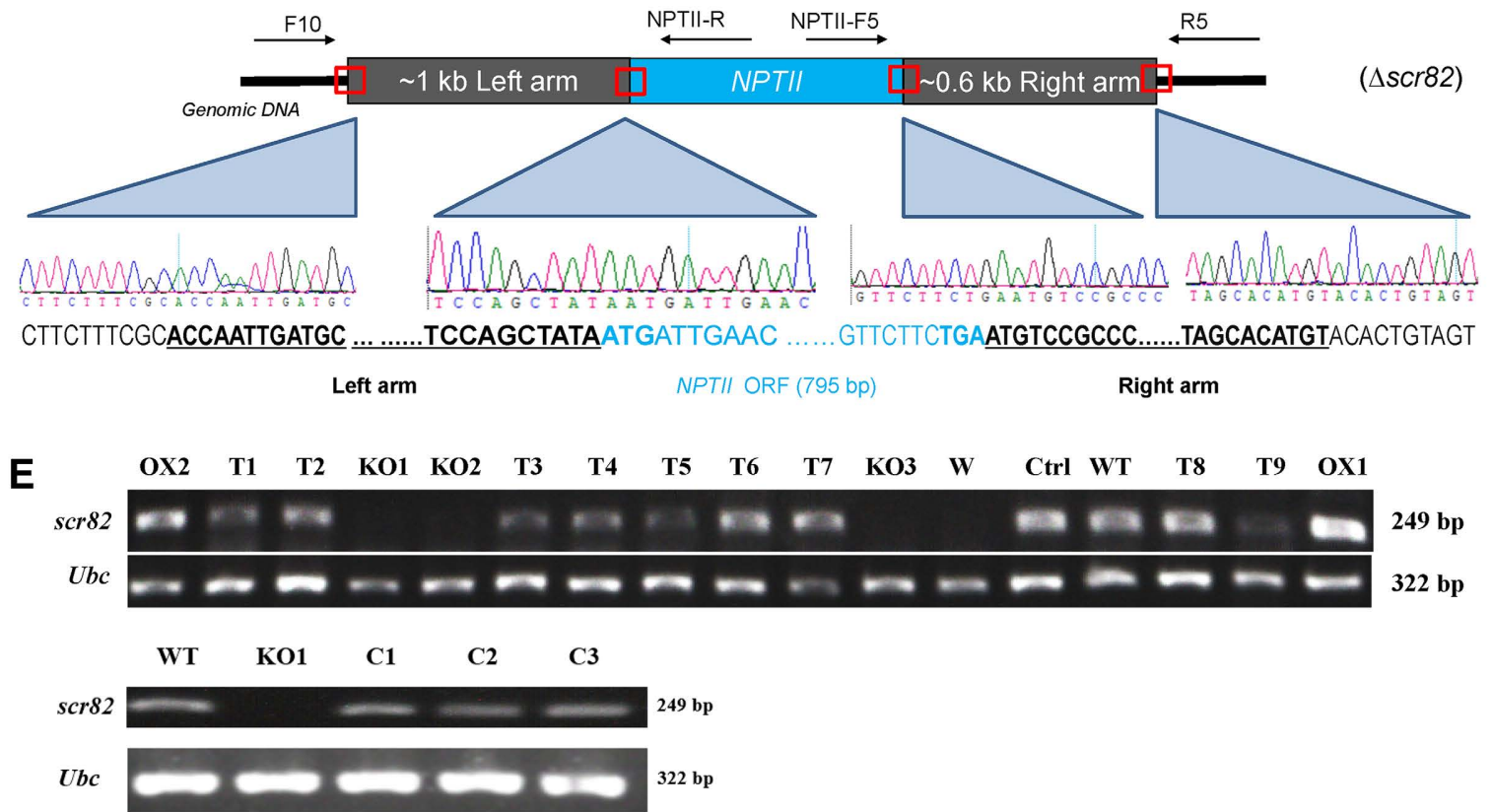

Fig. 7. scr82 is replaced by NPTII using the CRISPR/Cas9 system. A, The scr82 cutting loci selected for gene replacement by homology-directed repair (HDR) with the CRISPR/Cas9 system. SP = signal peptide. Two single-guide RNAs (sgRNAs) are boxed (sgRNA1) and underlined with green color (sgRNA2), respectively, and the protospacer adjacent motifs are bold. Seven cysteine residues are in red color. B, The strategy diagram of scr82 gene replacement using the CRISPR/Cas9 system. The wild-type Phytophthora capsici Pc537 (WT) genome was edited using sgRNA-Cas9 technology and the scr82 coding region was replaced with NPTII (geneticin-resistance gene) to obtain scr82 mutants. The sizes of the left and right arms are approximately 1 and 0.6 kb, respectively. Primer pairs F10/R5, F10/NPTII-R, and NPTII-F5/R5 were used for scr82 mutant screening. The red arrow indicates that the NcoI cleavage site that only exists in NPTII. C, PCR by three primer pairs and NcoI restriction enzyme analysis for screening of scr82 mutants. Lane $1=$ WT strain; lane $2=$ a non-HDR false-positive transformation control $(\mathrm{Ctrl})$; and lanes 3 to $5=$ the representative knockout strains KO1, KO2, and KO3, respectively. D, Sanger sequencing traces of junction regions confirming that scr82 was replaced by the NPTII gene in $P$. capsici mutants (e.g., in KO1 shown here). Start and stop codons of $N P T I I$ are indicated in bold and blue color. E, Hemiquantitative reverse-transcription PCR validation of $P$. capsici strains using scr82-specific primers with $3 \mathrm{~h}$ postinoculation cDNA. OX1 and $\mathrm{OX} 2=$ two scr82-overexpression transformants; $\mathrm{T} 1$ to $\mathrm{T} 9=$ nine transformants further unanalyzed; W = sterile water; $\mathrm{C} 1, \mathrm{C} 2$, and $\mathrm{C} 3=$ three scr82-complemented strains of $\mathrm{KO} 1$; and $U b c=$ the internal control. 
evidence suggests that $P$. capsici is one of the most genetically diverse eukaryotic organisms yet described, and its pathogenesis is more complex than originally considered (Kamoun et al. 2015). The genomic diversity and plasticity of $P$. capsici prompts speculation as to whether its highly diverse effector arsenal is important for host-specific interactions and the broad host range. In this study, a novel Phytophthora-specific PcF/SCR effector,
SCR82, was identified, and its biological functions in the interactions between $P$. capsici and its hosts were explored. We demonstrated the dual bioactivity of SCR82 toward host plants consisting of the defense-eliciting and virulent activity. In this view, SCR82 appears to function in a PcF-like manner (Nicastro et al. 2009; Orsomando et al. 2001, 2003, 2011) and, thus, its assignment into the PcF toxin family can be confirmed by the study.

A
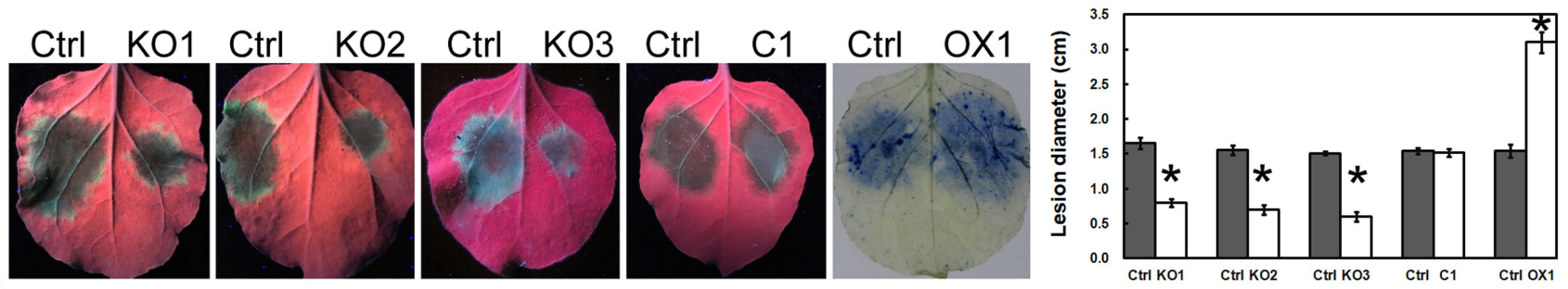

B
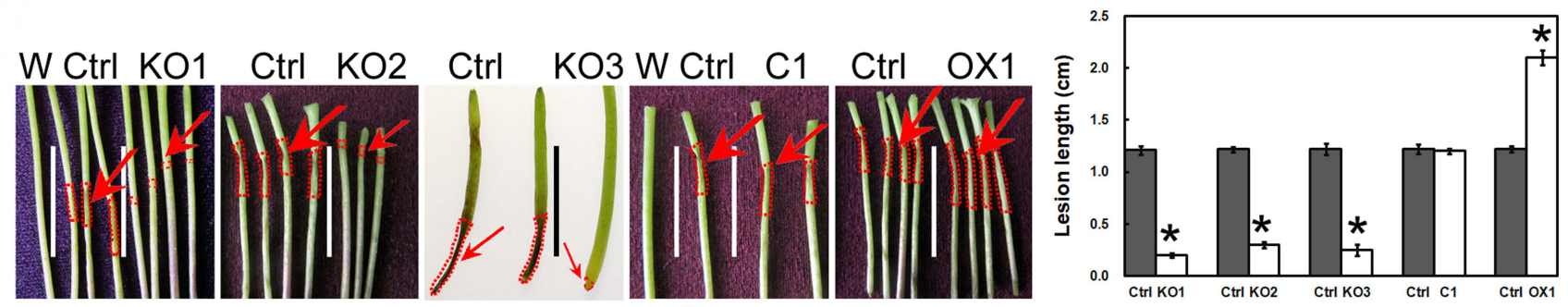

Fig. 8. SCR82 is an important virulent factor of Phytophthora capsici. Virulence activities of the $P$. capsici strains were tested on A, Nicotiana benthamiana leaves and $\mathbf{B}$, bell pepper stems. Statistical analysis of lesion size on each host was shown in the respective panel. Error bars are \pm standard error and the asterisks $\left(^{*}\right)$ denote statistically significant difference (Student's $t$ test, $P<0.01$ ). $P$. capsici strains inoculated: KO1 to KO3 = three CRISPR/Cas9-mediated scr82 knockout $(\mathrm{KO})$ transformants; $\mathrm{C} 1=\mathrm{KO} 1$ scr82-complemented transformant; OX1 = scr82-overexpression transformant; and Ctrl = transformation control. Sterile water inoculation (W) was used as a negative control. Arrows indicate the lesions in panels. Photographs were taken at $24 \mathrm{~h}$ postinoculation. Inoculated leaves were stained by trypan blue (A, the last panel) or observed under a UV light (the other four panels).

A

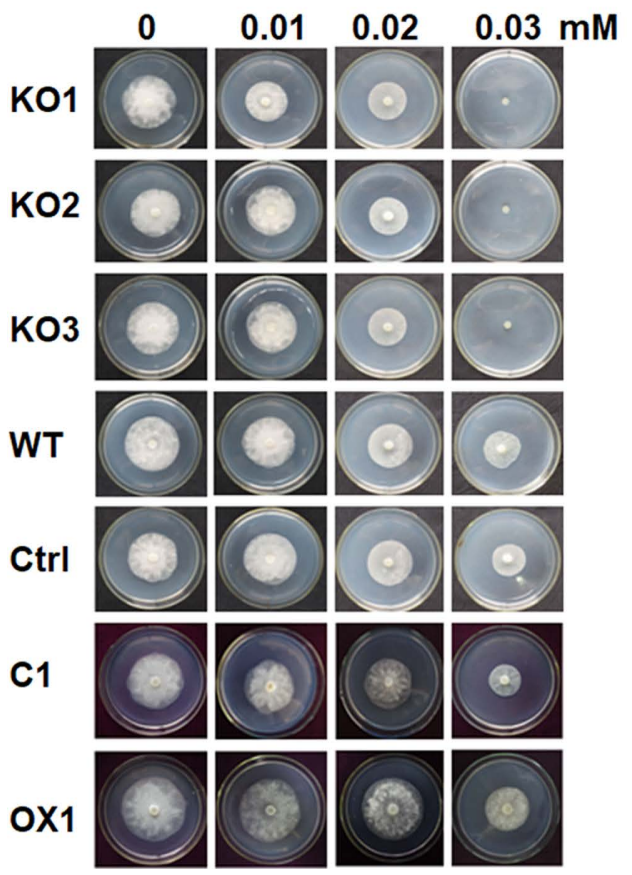

B

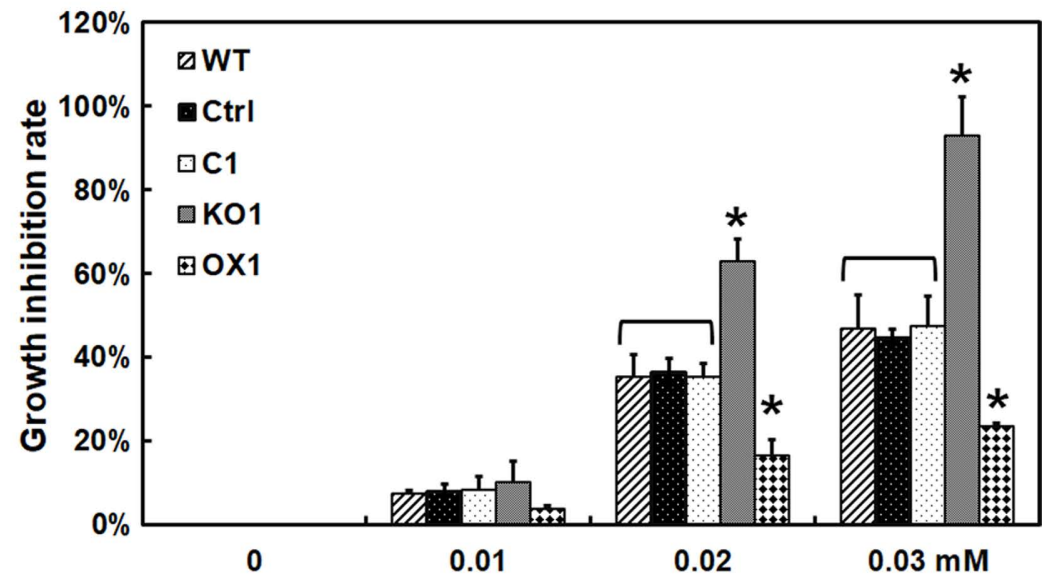

Fig. 9. Mycelial growth of Phytophthora capsici strains under the oxidative stress condition. A, P. capsici strains, including the wild-type (WT), transformation control (Ctrl), scr82-knockout strains (KO1, KO2, and KO3), scr82-complemented strain (C1, shown here), and scr82-overexpression transformant (OX1 shown here) were grown on Plich's agar medium supplemented with 0, 0.01, 0.02, and $0.03 \mathrm{mM}$ Cumeme hydroperoxide. B, Growth inhibition rates of P. capsici strains by the oxidant Cumeme hydroperoxide. Percentage values were calculated for each oxidant treatment $(0.01,0.02$, or $0.03 \mathrm{mM})$ relative to growth on Plich's medium without the oxidant. Error bars are \pm standard error and the asterisks $\left({ }^{*}\right)$ denote statistically significant difference between KO1, OX1, and the controls (WT, Ctrl, and C1) (Student's $t$ test, $P<0.01$ ). 
Transcriptional studies discovered that the genes encoding SCR82 and other family members (Chen et al. 2016, 2018; Liu et al. 2005) were differentially upregulated during the infection process, indicating their involvement in the pathogenesis of the pathogens. Previous studies showed that PcF/SCR effectors, including PcF, SCR96, SCR99, SCR113, and SCR121 from $P$. cactorum, caused PCD on host plants, including tomato, strawberry and $N$. benthamiana (Chen et al. 2016, 2018; Orsomando et al. 2001). Likewise, we found that $P$. capsici SCR82 can also induce PCD on tomato (but not on other plants) by Agrobacterium-mediated ectopic expression and yeast protein infiltration analyses. We speculated that tomato PCD induced by SCR82 is probably species specific. This protein family has been regarded as one class of phytotoxic proteins since the discovery of the first member (Orsomando et al. 2001, 2011; Wawra et al. 2012). In tomato, PcF also triggers activation of the key defense-related enzyme PAL and other $P R$ genes, as well as extracellular leakage of electrolytes (Orsomando et al. 2003, 2011). By yeast protein infiltration analysis, it was found that SCR82 triggers ROS burst and callose deposition, as well as the induction of defenserelated genes in tomato. The activated genes include not only $P A L$ and $P R$ genes but also FLS2 and PTI marker genes. These data indicate that plant defense responses, including PTI, were triggered by the treatment of SCR 82 in plants. However, these responses can't suggest a pattern receptor-based action mechanism and that PcF/SCR effectors could be of PAMPs because, thus far, no gene-for-gene model has been described (Nicastro et al. 2009; Orsomando et al. 2011).

$\mathrm{PcF} / \mathrm{SCR}$ effectors have been tentatively placed under the PcF toxin family based on their phytotoxicity. Increasing evidence suggests that PcF/SCR effectors function as virulence factors. For example, silencing of scr96 in P. cactorum led to the decreased virulence and resistance of the pathogen against oxidative stress (Chen et al. 2016). Like P. cactorum SCR96, SCR82 is an important virulence factor in $P$. capsici, as indicated by its strong expression during infection and the severe effect of the gene knockout. Overexpression of scr 82 increased the virulence of the pathogen on plants. Although SCR82 could trigger PCD, it was most strongly expressed at a very early stage of infection (biotrophic stage), when the pathogen presumedly suppresses cell death. The very strong and early expression of $s c r 82$ may indicate that it plays a role in physically facilitating invasion of the host tissue; alternatively, it helps obtain nutrition for the pathogen. As an apoplastic effector, SCR82 functions for the pathogen as an important virulence factor. Given that it may also be recognized by the plants as a PAMP, SCR82 blurs the distinction between PTI and ETI. This is quite similar to $P$. sojae XEG1 that acts as an important virulence factor during $P$. sojae infection but also acts as a PAMP in soybean and solanaceous species (Ma et al. 2015). This is also the case for NLP effectors that disrupt membranes by a pore-forming activity to induce necrosis and, meanwhile, evoke plant immune responses through an RLP23-SOBIR1BAK1 complex (Albert et al. 2015; Gijzen and Nürnberger 2006). Furthermore, knockout and overexpression assays showed that SCR82 is probably a positive regulator of ROS stress in the pathogen. This result is in accordance with our previous finding for $P$. cactorum SCR96 (Chen et al. 2016). Because it was found in the current study that the developmental characteristics, including sporangium production, zoospore release, and infection structure formation, were not disrupted in the scr82 KO mutants (also the case for SCR96), we speculated that PcF/SCR effectors such as SCR82 and SCR96 may contribute to the pathogens' virulence, probably through regulating ROS stress faced by the pathogens during the infections. Our recent transcriptome and proteome analyses showed us that plant peroxidase genes were significantly regulated by SCR96 treatment (unpublished data), strengthening this presumption. However, it needs further investigation.
SCR82 and other family members identified thus far possess dual bioactivity toward host plants during the infection. It was speculated that this protein family functions in plant apoplast space (Kamoun 2006; Wawra et al. 2012). Intriguingly, we found that $F L S 2$, encoding one of pattern-recognized receptors, was upregulated at early stages of rSCR82 treatment on tomato. The novel dual bioactivity could be better understood if their receptors in the apoplast or on the plant cell surface were identified. Thus far, their targets or receptors in plants have not been determined, although the SCR74 receptor was recently mapped to a 43-kbp G-LecRK locus in wild potato (Lin et al. 2020). Identification and characterization of plant targets of SCR 82 could be performed using molecular tools. Proteomics could be used on plasma membrane-enriched samples from tomato treated with rSCR82 and membrane-localized proteins upregulated upon the perception could be identified, following the protocol described by Yadeta et al. (2017). Alternatively, potential plant targets of SCR82 could be trapped using coimmunoprecipitation techniques.

Although a few members have been identified, progress on the functional analyses of PcF/SCR effectors is moving slowly. The main reasons behind this are the difficulties of conducting analyses on the effector proteins due to their nature and certain intrinsic obstacles, including small size, hydrophobicity, high content of cysteine residues and affinity-tag cleavage, or removal in apoplast of solanaceous species (Huang et al. 2020; Song 2007; van Esse et al. 2006). For example, we initially achieved the expression of SCR82 in bacteria and obtained the purified recombinant protein with a C-terminal SUMO tag using the pET28a(+) expression vector. However, the SUMO-tag (approximately $24 \mathrm{kDa}$ ) adversely affected the bioactivity of the recombinant protein in plants, though it is very useful to help in dissolving the recombinant protein (Zhang et al. 2019). In contrast, by heterologous expression in yeast using a C-terminal $\mathrm{His}_{6}$ tag (approximately $841 \mathrm{Da})$, the current study obtained recombinant protein with bioactivity, although the yield was lower than that produced by prokaryotic expression. We also found that a C-terminal His-tag without any linker is more reliable than other tags for studies of such proteins (unpublished data). In addition, we found that rSCR 82 produced by yeast cells is prone to aggregation probably due to its high cysteine content, giving a larger band (approximately $14 \mathrm{kDa}$, twice the size of the monomer) on the Western blot (WB) and silver staining gels. Furthermore, detection of SCR82 fused with the C-terminal $\mathrm{His}_{6}$ tag expressed in tomato leaves was not successful by WB using His antibody in the present study. This probably could be due to $\mathrm{His}_{6}$ tag cleavage or removal in the tomato apoplast, as described previously (Song 2007; van Esse et al. 2006), although further investigation is needed. Nevertheless, the yeast expression system could be improved for better yield and the resultant recombinant protein would be utilized for the function and structure analyses of the effector protein.

Although PcF/SCR effector sequences show extensive diversification without known domains or motifs, SCR82 seems conserved across Phytophthora spp. Two orthologs from $P$. infestans and one each from $P$. parasitica, $P$. cactorum, $P$. ramorum, $P$. palmivora, and $P$. cinnamomi but none from other species were found. Similarly, $P$. cactorum SCR96 was also found specific to oomycetes (Chen et al. 2016). Furthermore, allelic sequence analysis of scr82 in a population consisting of $44 P$. capsici isolates indicated that SCR82 may be under purifying selection pressure. This was supported by our finding that different SCR82 isoforms caused by sequence polymorphism didn't show distinct functions in developmental and infection process of $P$. capsici. It was worth noting that only transient expression of $s c r 82 \_1$ and $s c r 82 \_3$ but not others induced PCD in tomato leaves. More work is needed to determine whether the polymorphic sites in SCR82 isoforms were under purifying selection pressure. In contrast, positive selection evidence was observed within the SCR74 family of P. infestans (Liu 
et al. 2005), suggesting that distinct selective forces have shaped different PcF/SCR family members throughout the evolution of Phytophthora spp. The significance of sequence polymorphism of SCR82 in P. capsici could be the signature of purifying selection effect. Together with the dual bioactivity, SCR82 could be an important effector conserved across Phytophthora spp.

In summary, our work revealed a dual role of $P$. capsici $\mathrm{PcF} /$ SCR effector SCR82, consisting of defense-eliciting and virulence activity during the infection. However, the action mechanisms remain to be elucidated. Identification and characterization of plant targets or substrates of the effectors could help us to better understand the connection of dual bioactivity and their functions during the infection. Ultimately, the knowledge obtained from the studies will make it possible for us to elucidate the mechanism for how the pathogens take advantage of such diverse effectors to fulfill their purpose of plant infection and colonization.

\section{MATERIALS AND METHODS}

\section{Cultivation of Phytophthora isolates and plants.}

The $P$. capsici isolates (Supplementary Table S1) were routinely cultured on $10 \% \mathrm{~V} 8$ agar media at $25^{\circ} \mathrm{C}$ in the dark (Erwin and Ribeiro 1996). The WT isolate Pc537 was used in all experiments, while the other 43 isolates were used only for allelic sequence analysis. Cell types of $P$. capsici, including vegetative mycelia, sporangia, zoospores, and germinating cysts, was prepared as previously described (Chen et al. 2013). To test oxidative stress sensitivity, culture plugs $(5$ by $5 \mathrm{~mm}$ ) were placed onto Plich's agar containing Cumeme hydroperoxide $(0,0.01,0.02$, or $0.03 \mathrm{mM}$ ).

$N$. benthamiana, Capsicum annuum var. grossum (bell pepper), and Solanum lycopersicum 'L402' (tomato) were grown in a greenhouse under a regime of $16 \mathrm{~h}$ of light and $8 \mathrm{~h}$ of darkness at $22^{\circ} \mathrm{C}$. In the following assays, 2- to 6-week-old plants were used.

\section{Plant inoculation.}

A time course $(1.5,3,6,12,24,36$, and 72 hpi) of $P$. capsici infection was established to investigate the expression change of scr82 during the interaction with $N$. benthamiana plants. $N$. benthamiana plants grown in pots were watered $3 \mathrm{~h}$ prior to rhizosphere inoculation. Zoospore inoculation and sample harvesting were conducted as described (Chen et al. 2013).

To check the virulence activities of different strains (scr82 geneoverexpressed, $\mathrm{KO}$, and complemented transformants; WT; and Ctrl), zoospore suspensions (100 zoospores/ $\mu \mathrm{l})$ were inoculated onto abaxial sides of detached leaves of $N$. benthamiana (Chen et al. 2019). Seedling stems of bell pepper (roots removed) were inoculated by dipping them into zoospore suspensions for 4 $\mathrm{h}$ (Chen et al. 2019). Repeated inoculations, on independent occasions with different sets of plants, resulted in similar results.

\section{Nucleic acid manipulation, PCR, and RT-PCR.}

Genomic DNA was isolated from the Pc537 mycelia as described (Chen et al. 2019). Total RNA extraction and cDNA synthesis for four cell types (MY, SP, ZO, and GC) of $P$. capsici and plants and SYBR green qRT-PCR assays were performed as described (Chen et al. 2019). Hemiquantitative RT-PCR was conducted as described (Chen et al. 2016). The constitutively expressed $P$. capsici housekeeping gene $U b c$ (Chen et al. 2013) and tomato gene actin (GenBank accession number U60482) were used as the RT-PCR internal controls for their respective assays. The gene-specific primers are listed in Supplementary Table S2. To examine the expression changes across the infection course and life cycles, the expression level of scr82 in different samples was compared with the level of its expression in a calibrator sample, which was cDNA from mycelia.
To characterize the sequences of $s c r 82$ in $P$. capsici population, a 379-bp gene fragment containing its intact ORF (249 bp) was amplified from genomic DNAs of 44 isolates (Supplementary Table S1) using high-fidelity DNA polymerase (PrimeSTAR HS DNA polymerase; TaKaRa) and primer pair scr82-snpF/snpR. Taq polymerase (TaKaRa) was then added into the reaction to append a single $3^{\prime}-\mathrm{A}$ to each end of the PCR product, which was finally cloned into a linearized T-vector pMD19-T (TaKaRa). The inserts were sequenced at Sangon Biotech using universal M13 primers.

\section{Sequence analysis.}

The genome assembly (v11.0) of the $P$. capsici isolate LT1534 is accessible at the Department of Energy Joint Genome Institute. The protein sequence was tentatively translated from the cDNA sequence of scr82 using BioEdit (v7.2.0). Signal peptide was predicted using SignalP 3.0. BlastP ( $E \leq 1 \mathrm{e}-5)$ was used for homolog searches of the FungiDB, NCBI, and genome websites for several oomycetes. Sequence alignment was performed by BioEdit (50\% threshold for shading). Phylogenetic trees were generated by the neighbor-joining algorithm using MEGA (v7) with default parameters. Bootstrap support values were calculated from 1,000 heuristic search replicates.

\section{Plasmid construction.}

Plasmid construction was done following standard molecular techniques. All PCRs were conducted using PrimeSTAR HS DNA polymerase and specific primer pairs (Supplementary Table S2). The inserts of recombinant plasmids were verified by sequencing. For transient expression, a full-length ORF of scr82 was amplified from genomic DNA and cloned into the SmaI site of the PVX vector pGR107 (Jones et al. 1999) or pBINPLUS containing C-terminal $\mathrm{His}_{6}$. For SCR82 expression and purification, the sequence encoding mature SCR82 protein without its own signal peptide was in-fusion cloned into pPIC9K using SnaBI and primer pair scr82-pic9k-F/R.

Constructs used in $P$. capsici transformation assay were generated as follows. For scr82 overexpression and complementation, full-length scr82 was amplified using primers scr82-TOR-F/R, cut with the $C l a \mathrm{I}$ and $B s i \mathrm{WI}$ restriction enzymes, and inserted in the forward direction into pTORmRFP4 (Torche 2004). To knockout the scr82 gene, two plasmids, an "all-in-one" CRISPR/Cas9 plasmid pYF515 harboring both the $h \operatorname{SpCas} 9$ gene and the single-guide RNA (sgRNA) cassettes and a common plasmid vector pBluescript SK $\mathrm{II}^{+}$(Stratagene) containing homology-directed repair (HDR) donor template (namely, pBS-HDR-NPTII), were exploited. The EuPaGDT web tool (Peng and Tarleton, 2015) was used to select two 20-nucleotide sgRNAs, 5'-TGAAAGCCCT GAAGACAGTT-3' (sgRNA1) and 5'-GTCTAGCCAAACTGT CTTCA-3 ${ }^{\prime}$ (sgRNA2), targeting the $\mathrm{C}$ terminus of SCR82. Each of two sgRNA oligonucleotides was prepared and cloned into the NheI and BsaI sites of pYF515, as described (Fang et al. 2017). A segment of DNA consisting of genomic flanking sequences of scr82 (homology: left arm, approximately $1 \mathrm{~kb}$ and right arm, approximately $0.6 \mathrm{~kb}$ ) on each side of the donor DNA (NPTII gene) was assembled by overlap PCR and inserted into pBluescript $\mathrm{SK} \mathrm{II}^{+}$through the EcoRV and BamHI sites following the procedure provided by Fang et al. (2017).

\section{A. tumefaciens-mediated transient expression.}

All binary plasmids were introduced into A. tumefaciens strain GV3101 for transient protein expression in tomato, bell pepper, and $N$. benthamiana. Preparation of agrobacteria cells and leaf infiltrations were conducted as described by Chen et al. (2016). Assays for each plasmid consisted of six plants inoculated on 5 leaves (for a total of 30 leaves). After infiltration, symptom development was monitored at an interval of 3 to 15 days. Repeated 
infiltrations, on independent occasions with different sets of plants, yielded similar results.

\section{Expression and purification of rSCR82 protein.}

The strain KM71 (Invitrogen) of Pichia pastoris was used as the expression host. Yeast cultures were maintained on yeast extract-peptone-dextrose medium. To increase protein expression, $P$. pastoris transformants containing multicopy inserts of scr82 were screened using the resistance present on pPIC9K to G418 sulfate (Geneticin) following the manufacturer's protocol. Buffered glycerol-complex medium and buffered methanol-complex medium, both at $\mathrm{pH}$ 6.0, were used for yeast growth and induction, respectively (EasySelectPichia Expression Kit; Invitrogen). Induction of protein expression was performed according to the manufacturer's instructions. rSCR82 protein was purified from the culture supernatant by affinity chromatography using HighAffinity Ni-NTA Resin (GenScript Biotech) and checked on sodium dodecyl sulfate polyacrylamide gel electrophoresis (SDS-PAGE) gel by silver staining. The protein concentration was measured using an enhanced BCA protein kit (Beyotime Biotech)

\section{Immunoblotting.}

To extract protein, agroinfiltrated plant leaves were ground into fine powder with liquid nitrogen using a mortar and a pestle. Approximately $500 \mu \mathrm{l}$ of powder was added to $700 \mu \mathrm{l}$ of loading buffer (4\% SDS, 10\% 2-mercaptoethanol, 20\% glycerol, $0.004 \%$ bromophenol blue, and $125 \mathrm{mM}$ Tris- $\mathrm{HCl}, \mathrm{pH}$ 6.8) on ice. The mixture was violently vortexed for 10 to $20 \mathrm{~s}$, boiled for 5 to 10 min, then kept on ice for 5 to $10 \mathrm{~min}$. After centrifugation at $12,000 \mathrm{rpm}$ for $10 \mathrm{~min}$ at $4^{\circ} \mathrm{C}$, the supernatant was taken to another tube on ice.

Standard SDS-PAGE gel electrophoresis, protein transfer from the gel to nitrocellulose filter membrane $(0.22-\mu \mathrm{m}$ pore size) (Pall Corporation), membrane blocking, and protein detection were performed as described (Chen et al. 2019). Protein expression in yeast and plants was detected using anti-His ${ }_{6}$-tag primary monoclonal antibody (Sino Biological Inc.).

\section{Phytophthora capsici transformation.}

Gene knockout via HDR pathway was performed with equal molar quantities of pYF515 and pBS-HDR-NPTII following the CRISPR/Cas9 protocol described by Fang et al. (2017). Gene complementation was conducted by introducing pTORmRFP4scr82 into the gene knockout mutant $\mathrm{KO} 1$ that lacked G418 resistance after several generations of subculture without G418 selection (Fang et al. 2017). Gene overexpression was achieved by introducing pTORmRFP4-scr82 into the isolate Pc537. Stable protoplast transformation mediated by polyethylene glycol was used to introduce plasmid DNAs into Phytophthora capsici as described (Chen et al. 2019; Fang et al. 2017). Transformants were screened as described (Chen et al. 2019; Fang et al. 2017).

\section{Staining of DAB, aniline blue, and trypan blue.}

Tomato leaves were infiltrated with $40 \mu$ of purified rSCR82 solution (no dilution $[140 \mu \mathrm{M}]$ and a serial 1:2 dilution) or an equal volume of $1 \times$ phosphate-buffered saline buffer control using a 1-ml syringe without its needle and detached at designated time points. To observe the accumulation of ROS, treated leaves were immersed in $0.1 \%$ DAB ( $\mathrm{pH} 3.8)$ (TaKaRa) for $8 \mathrm{~h}$ in the dark at $25^{\circ} \mathrm{C}$ for staining. Each leaf was then boiled in $95 \%$ ethanol for 10 min for destaining and observed by the naked eye.

To determine the presence of callose deposits, treated leaves were soaked in destaining solution (phenol/glycerol/lactate/ water/ethanol, 1:1:1:1:8 [vol/vol/vol/vol/vol]), infiltrated by applying a vacuum for 5 to $10 \mathrm{~min}$, and boiled at $100^{\circ} \mathrm{C}$ until all chlorophyll was cleared. Leaves were gently rinsed with water and then vacuum treated in $0.01 \%$ aniline blue solution $(150$ $\mathrm{mM} \mathrm{K}_{2} \mathrm{HPO}_{4}, \mathrm{pH}$ 9.5) (TaKaRa) for 5 to $10 \mathrm{~min}$ and placed in the dark for $8 \mathrm{~h}$ at $25^{\circ} \mathrm{C}$. After staining, leaves were gently rinsed in water and inoculation sites were photographed using a fluorescence microscope.

To detect leaf cell death of $N$. benthamiana, trypan blue staining was performed as described (Chen et al. 2016). Briefly, the leaves were soaked in Farmer's solution (95\% ethanol/chloroform/glacial acetic acid, 6:3:1 [vol/vol/vol]) for $30 \mathrm{~s}, 0.05 \%$ trypan blue mixture (Sigma-Aldrich) for $8 \mathrm{~h}$ in the darkness, and then destained by ethanol.

\section{Data availability statement.}

The data that support the findings of this study are available from the corresponding author upon reasonable request.

\section{AUTHOR-RECOMMENDED INTERNET RESOURCES}

Department of Energy Joint Genome Institute: https://mycocosm.jgi.doe.gov/Phyca11/Phyca11.home.html

SignalP 3.0: http://www.cbs.dtu.dk/services/SignalP-3.0/

FungiDB: https://fungidb.org

NCBI: https://www.ncbi.nlm.nih.gov

\section{LITERATURE CITED}

Albert, I., Böhm, H., Albert, M., Feiler, C. E., Imkampe, J., Wallmeroth, N., Brancato, C., Raaymakers, T. M., Oome, S., Zhang, H., Krol, E., Grefen, C., Gust, A. A., Chai, J., Hedrich, R., Van den Ackerveken, G., and Nürnberger, T. 2015. An RLP23-SOBIR1-BAK1 complex mediates NLP-triggered immunity. Nat. Plants 1:15140.

Baxter, L., Tripathy, S., Ishaque, N., Boot, N., Cabral, A., Kemen, E., Thines, M., Ah-Fong, A., Anderson, R., Badejoko, W., Bittner-Eddy, P., Boore, J. L., Chibucos, M. C., Coates, M., Dehal, P., Delehaunty, K., Dong, S., Downton, P., Dumas, B., Fabro, G., Fronick, C., Fuerstenberg, S. I., Fulton, L., Gaulin, E., Govers, F., Hughes, L., Humphray, S., Jiang, R. H. Y., Judelson, H., Kamoun, S., Kyung, K., Meijer, H., Minx, P., Morris, P., Nelson, J., Phuntumart, V., Qutob, D., Rehmany, A., Rougon-Cardoso, A., Ryden, P., Torto-Alalibo, T., Studholme, D., Wang, Y., Win, J., Wood, J., Clifton, S. W., Rogers, J., Van den Ackerveken, G., Jones, J. D. G., McDowell, J. M., Beynon, J., and Tyler, B. M. 2010. Signatures of adaptation to obligate biotrophy in the Hyaloperonospora arabidopsidis genome. Science 330 1549-1551.

Bos, J. I. B., Armstrong, M., Whisson, S. C., Torto, T. A., Ochwo, M., Birch, P. R. J., and Kamoun, S. 2003. Intraspecific comparative genomics to identify avirulence genes from Phytophthora. New Phytol. 159:63-72.

Bozkurt, T. O., Schornack, S., Banfield, M. J., and Kamoun, S. 2012. Oomycetes, effectors, and all that jazz. Curr. Opin. Plant Biol. 15:483492.

Chen, X. R., Huang, S. X., Zhang, Y., Sheng, G. L., Zhang, B. Y., Li, Q. Y., Zhu, F., and Xu, J. Y. 2018. Transcription profiling and identification of infection-related genes in Phytophthora cactorum. Mol. Genet. Genomics 293:541-555.

Chen, X. R., Li, Y. P., Li, Q. Y., Xing, Y. P., Liu, B. B., Tong, Y. H., and Xu, J. Y. 2016. SCR96, a small cysteine-rich secretory protein of Phytophthora cactorum, can trigger cell death in the Solanaceae and is important for pathogenicity and oxidative stress tolerance. Mol. Plant Pathol. 17:577-587.

Chen, X. R., Xing, Y. P., Li, Y. P., Tong, Y. H., and Xu, J. Y. 2013. RNASeq reveals infection-related gene expression changes in Phytophthora capsici. PLoS One 8:e74588.

Chen, X. R., Zhang, Y., Li, H. Y., Zhang, Z. H., Sheng, G. L., Li, Y. P., Xing, Y. P., Huang, S. X., Tao, H., Kuan, T., Zhai, Y., and Ma, W. 2019. The RXLR effector PcAvh1 is required for full virulence of Phytophthora capsici. Mol. Plant-Microbe Interact. 32:986-1000.

Couto, D., and Zipfel, C. 2016. Regulation of pattern recognition receptor signalling in plants. Nat. Rev. Immunol. 16:537-552.

Delport, W., Poon, A. F., Frost, S. D., and Kosakovsky Pond, S. L. 2010 Datamonkey 2010: A suite of phylogenetic analysis tools for evolutionary biology. Bioinformatics 26:2455-2457. 
Erwin, D. C., and Ribeiro, O. K. 1996. Phytophthora Diseases Worldwide. American Phytopathological Society, St. Paul, MN, U.S.A.

Fang, Y., Cui, L., Gu, B., Arredondo, F., and Tyler, B. M. 2017. Efficient genome editing in the oomycete Phytophthora sojae using CRISPR/ Cas9. Curr. Protoc. Microbiol. 44:21A.1.1-21A.1.26.

Gamboa-Meléndez, H., Huerta, A. I., and Judelson, H. S. 2013. bZIP transcription factors in the oomycete Phytophthora infestans with novel DNA-binding domains are involved in defense against oxidative stress. Eukaryot. Cell 12:1403-1412.

Gao, J., Cao, M., Ye, W., Li, H., Kong, L., Zheng, X., and Wang, Y. 2015 PsMPK7, a stress-associated mitogen-activated protein kinase (MAPK) in Phytophthora sojae, is required for stress tolerance, reactive oxygenated species detoxification, cyst germination, sexual reproduction and infection of soybean. Mol. Plant Pathol. 16:61-70.

Gijzen, M., and Nürnberger, T. 2006. Nep1-like proteins from plant pathogens: Recruitment and diversification of the NPP1 domain across taxa. Phytochemistry 67:1800-1807.

Gómez-Gómez, L., Felix, G., and Boller, T. 1999. A single locus determines sensitivity to bacterial flagellin in Arabidopsis thaliana. Plant J. 18:277-284.

Haas, B. J., Kamoun, S., Zody, M. C., Jiang, R. H., Handsaker, R. E., Cano, L. M., Grabherr, M., Kodira, C. D., Raffaele, S., Torto-Alalibo, T., Bozkurt, T. O., Ah-Fong, A. M., Alvarado, L., Anderson, V. L., Armstrong, M. R., Avrova, A., Baxter, L., Beynon, J., Boevink, P. C., Bollmann, S. R., Bos, J. I., Bulone, V., Cai, G., Cakir, C., Carrington, J. C., Chawner, M., Conti, L., Costanzo, S., Ewan, R., Fahlgren, N., Fischbach, M. A., Fugelstad, J., Gilroy, E. M., Gnerre, S., Green, P. J., Grenville-Briggs, L. J., Griffith, J., Grünwald, N. J., Horn, K., Horner, N. R., Hu, C. H., Huitema, E., Jeong, D. H., Jones, A. M., Jones, J. D., Jones, R. W., Karlsson, E. K., Kunjeti, S. G., Lamour, K., Liu, Z., Ma, L., Maclean, D., Chibucos, M. C., McDonald, H., McWalters, J., Meijer, H. J., Morgan, W., Morris, P. F., Munro, C. A., O’Neill, K., Ospina-Giraldo, M., Pinzón, A., Pritchard, L., Ramsahoye, B., Ren, Q., Restrepo, S., Roy, S., Sadanandom, A., Savidor, A., Schornack, S., Schwartz, D. C., Schumann, U. D., Schwessinger, B., Seyer, L., Sharpe, T., Silvar, C., Song, J., Studholme, D. J., Sykes, S., Thines, M., van de Vondervoort, P. J., Phuntumart, V., Wawra, S., Weide, R., Win, J., Young, C., Zhou, S., Fry, W., Meyers, B. C., van West, P., Ristaino, J., Govers, F., Birch, P. R., Whisson, S. C., Judelson, H. S., and Nusbaum, C. 2009. Genome sequence and analysis of the Irish potato famine pathogen Phytophthora infestans. Nature 461: 393-398.

Huang, S. X., Zhang, Z. H., Liu, W., Tao, H., Zhang, Y., Shi, N. X., Zhu, F., Ji, Z. L., and Chen, X. R. 2020. Expression of the small cysteine-rich protein SCR96 from Phytophthora cactorum in mammalian cells: Phytotoxicity and exploitation of its polyclonal antibody. Biotechnol. Lett. 42:125-133.

Jones, J. D. G., and Dangl, J. L. 2006. The plant immune system. Nature 444:323-329.

Jones, L., Hamilton, A. J., Voinnet, O., Thomas, C. L., Maule, A. J., and Baulcombe, D. C. 1999. RNA-DNA interactions and DNA methylation in post-transcriptional gene silencing. Plant Cell 11:2291-2301.

Kamoun, S. 2006. A catalogue of the effector secretome of plant pathogenic oomycetes. Annu. Rev. Phytopathol. 44:41-60.

Kamoun, S., Furzer, O., Jones, J. D., Judelson, H. S., Ali, G. S., Dalio, R. J., Roy, S. G., Schena, L., Zambounis, A., Panabières, F., Cahill, D., Ruocco, M., Figueiredo, A., Chen, X. R., Hulvey, J., Stam, R., Lamour, K., Gijzen, M., Tyler, B. M., Grünwald, N. J., Mukhtar, M. S., Tomé, D. F., Tör, M., Van Den Ackerveken, G., McDowell, J., Daayf, F., Fry, W. E., Lindqvist-Kreuze, H., Meijer, H. J., Petre, B., Ristaino, J., Yoshida, K., Birch, P. R., and Govers, F. 2015. The Top 10 oomycete pathogens in molecular plant pathology. Mol. Plant Pathol. 16:413-434.

Kosakovsky Pond, S. L., and Frost, S. D. 2005. Not so different after all: A comparison of methods for detecting amino acid sites under selection. Mol. Biol. Evol. 22:1208-1222.

Lamb, C., and Dixon, R. A. 1997. The oxidative burst in plant disease resistance. Annu. Rev. Plant Physiol. Plant Mol. Biol. 48:251-275.

Lamour, K. H., Stam, R., Jupe, J., and Huitema, E. 2012. The oomycete broad-host-range pathogen Phytophthora capsici. Mol. Plant Pathol. 13:329-337.

Lévesque, C. A., Brouwer, H., Cano, L., Hamilton, J. P., Holt, C., Huitema, E., Raffaele, S., Robideau, G. P., Thines, M., Win, J., Zerillo, M. M., Beakes, G. W., Boore, J. L., Busam, D., Dumas, B., Ferriera, S., Fuerstenberg, S. I., Gachon, C. M., Gaulin, E., Govers, F., Grenville-Briggs, L., Horner, N., Hostetler, J., Jiang, R. H., Johnson, J., Krajaejun, T., Lin, H., Meijer, H. J., Moore, B., Morris, P., Phuntmart, V., Puiu, D., Shetty, J., Stajich,
J. E., Tripathy, S., Wawra, S., van West, P., Whitty, B. R., Coutinho, P. M., Henrissat, B., Martin, F., Thomas, P. D., Tyler, B. M., De Vries, R. P., Kamoun, S., Yandell, M., Tisserat, N., and Buell, C. R. 2010. Genome sequence of the necrotrophic plant pathogen Pythium ultimum reveals original pathogenicity mechanisms and effector repertoire. Genome Biol. 11:R73.

Levine, A., Tenhaken, R., Dixon, R., and Lamb, C. 1994. $\mathrm{H}_{2} \mathrm{O}_{2}$ from the oxidative burst orchestrates the plant hypersensitive disease resistance response. Cell 79:583-593.

Lin, X., Armstrong, M., Baker, K., Wouters, D., Visser, R. G. F., Wolters, P. J., Hein, I., and Vleeshouwers, V. G. A. A. 2020. RLP/K enrichment sequencing; a novel method to identify receptor-like protein (RLP) and receptor-like kinase (RLK) genes. New Phytol. 227:1264-1276.

Liu, Z., Bos, J. I., Armstrong, M., Whisson, S. C., da Cunha, L., Torto-Alalibo, T., Win, J., Avrova, A. O., Wright, F., Birch, P. R., and Kamoun, S. 2005. Patterns of diversifying selection in the phytotoxin-like scr74 gene family of Phytophthora infestans. Mol. Biol. Evol. 22:659-672.

Ma, Z., Song, T., Zhu, L., Ye, W., Wang, Y., Shao, Y., Dong, S., Zhang, Z., Dou, D., Zheng, X., Tyler, B. M., and Wang, Y.2015. A Phytophthora sojae glycoside hydrolase 12 protein is a major virulence factor during soybean infection and is recognized as a PAMP. Plant Cell 27:2057-2072.

Monaghan, J., and Zipfel, C. 2012. Plant pattern recognition receptor complexes at the plasma membrane. Curr. Opin. Plant Biol. 15:349-357.

Nicastro, G., Orsomando, G., Ferrari, E., Manconi, L., Desario, F., Amici, A., Naso, A., Carpaneto, A., Pertinhez, T. A., Ruggieri, S., and Spisni, A. 2009. Solution structure of the phytotoxic protein PcF: The first characterized member of the Phytophthora PcF toxin family. Protein Sci. 18: 1786-1791.

Orsomando, G., Brunetti, L., Pucci, K., Ruggeri, B., and Ruggieri, S. 2011. Comparative structural and functional characterization of putative protein effectors belonging to the PcF toxin family from Phytophthora spp. Protein Sci. 20:2047-2059.

Orsomando, G., Lorenzi, M., Ferrari, E., de Chiara, C., Spisni, A., and Ruggieri, S. 2003. PcF protein from Phytophthora cactorum and its recombinant homologue elicit phenylalanine ammonia lyase activation in tomato. Cell. Mol. Life Sci. 60:1470-1476.

Orsomando, G., Lorenzi, M., Raffaelli, N., Dalla Rizza, M., Mezzetti, B., and Ruggieri, S. 2001. Phytotoxic protein PcF, purification, characterization, and cDNA sequencing of a novel hydroxyproline-containing factor secreted by the strawberry pathogen Phytophthora cactorum. J. Biol. Chem. 276:21578-21584.

Peng, D., and Tarleton, R. 2015. EuPaGDT: A web tool tailored to design CRISPR guide RNAs for eukaryotic pathogens. Microb. Genomics 1: e000033.

Song, J. 2007. Functional characterization of extracellular protease inhibitors of Phytophthora spp. and their targets tomato proteases. Ph.D. thesis, Ohio State University.

Stassen, J. H., and Van den Ackerveken, G. 2011. How do oomycete effectors interfere with plant life? Curr. Opin. Plant Biol. 14:407-414.

Stergiopoulos, I., and de Wit, P. J. G. M. 2009. Fungal effector proteins. Annu. Rev. Phytopathol. 47:233-263.

Torche, S. 2004. Isolation et etudes d'expression de genes potentiellement lis a la pathogenicite chez Phytophthora porri. Ph.D. Thesis, Switzerland, University of Friborg.

Tyler, B. M., Tripathy, S., Zhang, X., Dehal, P., Jiang, R. H., Aerts, A., Arredondo, F. D., Baxter, L., Bensasson, D., Beynon, J. L., Chapman, J., Damasceno, C. M., Dorrance, A. E., Dou, D., Dickerman, A. W., Dubchak, I. L., Garbelotto, M., Gijzen, M., Gordon, S. G., Govers, F., Grunwald, N. J., Huang, W., Ivors, K. L., Jones, R. W., Kamoun, S., Krampis, K., Lamour, K. H., Lee, M. K., McDonald, W. H., Medina, M., Meijer, H. J., Nordberg, E. K., Maclean, D. J., Ospina-Giraldo, M. D., Morris, P. F., Phuntumart, V., Putnam, N. H., Rash, S., Rose, J. K., Sakihama, Y., Salamov, A. A., Savidor, A., Scheuring, C. F., Smith, B. M., Sobral, B. W., Terry, A., Torto-Alalibo, T. A., Win, J., Xu, Z., Zhang, H., Grigoriev, I. V., Rokhsar, D. S., and Boore, J. L. 2006. Phytophthora genome sequences uncover evolutionary origins and mechanisms of pathogenesis. Science 313:1261-1266.

van Esse, H. P., Thomma, B. P., van 't Klooster, J. W., and de Wit, P. J. 2006. Affinity-tags are removed from Cladosporium fulvum effector proteins expressed in the tomato leaf apoplast. J. Exp. Bot. 57:599-608.

Wang, W., and Jiao, F. 2019. Effectors of Phytophthora pathogens are powerful weapons for manipulating host immunity. Planta 250:413-425.

Wang, Y., Tyler, B. M., and Wang, Y. 2019. Defense and counterdefense during plant-pathogenic oomycete infection. Annu. Rev. Microbiol. 73:667-696.

Wang, Y., and Wang, Y. 2018. Trick or treat: Microbial pathogens evolved apoplastic effectors modulating plant susceptibility to infection. Mol. Plant-Microbe Interact. 31:6-12. 
Wawra, S., Belmonte, R., Löbach, L., Saraiva, M., Willems, A., and van West, P. 2012. Secretion, delivery and function of oomycete effector proteins. Curr. Opin. Microbiol. 15:685-691.

Yadeta, K. A., Elmore, J. M., Creer, A. Y., Feng, B., Franco, J. Y., Rufian, J. S., He, P., Phinney, B., and Coaker, G. 2017. A cysteine-rich protein kinase associates with a membrane immune complex and the cysteine residues are required for cell death. Plant Physiol. 173:771-787.
Yang, Z. 2007. PAML 4: Phylogenetic analysis by maximum likelihood. Mol. Biol. Evol. 24:1586-1591.

Zhang, Z. H., Huang, S. X., Tao, H., Zhang, Y., Zhao, Y., Ji, Z. L., and Chen, X. R. 2019. Gene transcriptional pattern, prokaryotic expression and functional analysis of an apoplastic, hydrophobic and small effector SCR82 from Phytophthora capsici. Acta Microbiol. Sin. 59: 1586-1599. 